\title{
A Comparison of Chinese and English Compliments*
}

\author{
Rongmei Yu \\ NanChang Normal University, China
}

\begin{abstract}
It is particularly known that more interactions of people all around the world are on more broader level with the development of society. People are able to exchange their ideas or positive feelings with each other with different languages. We know that the language carries the culture, and different cultures will cause the speech act expressed with the different ways. Therefore, as a speech act, compliments in various languages are also covered by the cultures all over the world. Duo to the differences of cultural background, the customary culture and factors of cultural judgement vary from nations, so that people should pay more attention to the ways of compliments and responds. Compliment has its specific meaning and functions both in Chinese and English, as well as other languages. However, language environment is too important to be without for compliment and the expression of compliment response also varies from different cultural context. In addition, people have various emphasis when they compliment others, Sometimes, not all compliments will be considered to be a praise, if the compliments aren't expressed in proper ways, the recipients may feel ill at ease, even irritated. In order to use the compliments in appropriate ways and make responds properly to attain expected effects, the author is mainly to make comparison between Chinese and English compliments. The comparison contains complimentary contents, such as appearance, weight, friendship and possession, response patterns and characteristics of Chinese and English compliment responses. The author also wants to mater the skills of appropriate compliment expression by contrasting Chinese and English compliment on some aspects.
\end{abstract}

Index Terms - compliment, complimentary contents, semantic structures, compliment response, Chinese and English

\section{INTRODUCTION}

People all know that compliment is a quite universal linguistic phenomenon which with a wide range of applications and a high frequency of use. It is applied to attain many different purposes like congratulations, greetings, invitations in different countries. As a social communication language, the compliments can not only shorten the social distance between communicators, but also can make friendly contacts and maintain normal social relationship. In different cultural background, the communicative function of compliments cannot be neglected, because compliments can produce positive effect on interpersonal relationship if they're used in proper occasions. Identically, the compliment response also plays an indispensable role in social communication. If the respondents don't take appropriate compliment response strategies, the compliments may have contrary influence. In order to avoid the embarrassment, misunderstanding, confusion in intercultural communication and strengthen the social relationship between communicators by using compliments. Therefore, making a contrastive analysis of Chinese and English compliments and their response uses from different aspects will help people get some knowledge of compliments and their responses in different occasions or among different people and can establish and maintain harmonious interpersonal relations in cross-cultural communication.

Many scholars at home and abroad have studied compliments and compliments responses from different aspects. For example, Shi Jiawei has summarized the main sentence structure of Chinese and English compliments and also put forward that people in the west often praise their family members. While in China, it's contrary to the West. The closer they are, the less compliments between them. Cen Jing proposed four factors that have influence on the patterns of compliment response through analyzing the cultural differences' influence on language production. These four factors are social status, correlation, topic of the conversation and age of communicators. And He Mingzhi considered that the compliment response could be divided into three categories, these are Direct acceptance, Corrective acceptance and Nonacceptance. Besides, according to the survey data of American linguistic scholars, like Wolfson, manes and Herbert, Wang Jijie and Xu Zhenghua drew some conclusions under the condition of comparison with Chinese compliment. They found that about 43.1percents Chinese compliment response can be converged into Herbert's six kinds of agreed response strategies and 31.3percents compliments and their response strategies have Chinese characteristics. Tang Aijun and Huang Jianbin's reserch on compliment responses among Chinese showed about 11percents people accept compliments directly, 14.7 percents accept indirectly, and the rest are refusing compliments. That is to say, the majority of Chinese people choose to refuse when they meet someone's compliments, but the west often say these kinds of

\footnotetext{
${ }^{*}$ This paper is funded by 11531 project of Nanchang Normal University
} 
responses are dishonest. In addition, the foreign scholars, like Pomerantz and Herbert have done much research on compliment responses and Pomerantz attributed the form of compliment responses to two conflicting principles. The first one is Agreement, the other is Avoid self-praise.

In this thesis, the most difficult matter is to make a comprehensive understanding of Chinese and English differences in compliments use through large amounts of scholars' research and survey data and summary the author's own opinions. As a Chinese, it's very easy to understand the cultural values of compliments in various aspects, especially in our daily life. But as a person who regards English as a second language, it's difficult to understand English cultural values in compliments. Therefore, the more correlative knowledge people get, the easier to master English compliment skills. This thesis focuses on comparison of English and Chinese compliments in part of its bearings. The author wants to draw some conclusion by making a comparison to make the contrast more vivid, concrete and easier to understand so that people can apply compliments and compliment responses to social communication under perfect control.

\section{COMPLimENTS AND COMPLimENT RESPONSES}

As we all know, compliment is a common phenomenon in all kinds of languages. They play a vital part in interaction, especially in international activities. In order to get acknowledgement of this speech act, the author is going to analyze the definition and functions of compliments and their responses.

\section{A. The Definition of Compliment}

"Compliments, as a kind of speech act, is considered to be closely related to politeness. It is the expression of praise, admiration, approval, etc.”(Oxford Dictionary,1997, p.283).In Modern Chinese Dictionary: “Compliment, a verb, means to convey someone' love to the advantages of people or things with words."(version5, 2010, p.171). A compliment is a speech act which explicitly or implicitly bestows credit upon the addressee for some possession, skill, characteristic, or the like, that is positively evaluated by the speaker and addressee. Compliment is a quite universal linguistic phenomenon which with a wide range of applications and a high frequency of use. In short, compliment is a kind of speech act to show the speaker's appreciation, agreement, support and admiration to others. What's more, compliments can also start topics, end conversations naturally and even can get rid of embarrassing situations..Unlike the other speeches, compliments are barely filled with negative vocabulary. In general, compliments include two parts: the speaker's complimentary contents and the responds of the recipient. Therefore, it's not difficult to find that compliments and compliment responses are "adjacency pairs". They must appear as rational and targeted pairs, or compliments cannot attain the expected effect.

\section{B. The Functions of Compliment and Compliment Responses}

It is universally acknowledged that the compliments can not only shorten the social distance between communicators, but also can make friendly contacts and maintain normal social relationship."Compliments can act as the complements of greeting; and sometimes, compliments can strengthen the appreciation; compliments can start or end conversations. The proper topics that started by compliments are able to activate the recipients interested in; compliments can also create a harmonious atmosphere for the speakers and recipients to express the nice wishes. Therefore, compliments are able to push forward the conversations, get rid of dilemma and eliminate estrangement. Furthermore, compliments can be applied to persuade and encourage someone."(Xi Yuxia, 2009). Identically, appropriate responses can make the same effect, because compliments and compliment responses are "adjacency pairs". That's to say, compliment responses are to compliments what lips are to teeth. Both do coexist so that they can have the same effect.

\section{COMPARISON OF ENGLISH AND CHINESE COMPLIMENTS}

Compliment is a common-used speech act. When it comes to compliment between Chinese and English, most people believed that Chinese is reserved and it's rarely to see a native Chinese speaker compliments someone directly, while English is prefer to show their emotions without hesitation. The reason why they differ in many aspects is that compliment, as a speech act, is covered by different cultural backgrounds. There will cause opposite influences and let the speakers or recipients get into embarrassing situations in daily interaction, international interaction in deposits. Consequently, the author wants to make comparison on complimentary contents and complimentary forms of Chinese and English compliments to avoid misunderstanding and embarrassment.

\section{A. Complimentary Contents of Chinese and English Compliments}

Compliment, as a speech act, it's not only show praise for something or someone, but also reflects the social and cultural values of the users. Different values cause differences. The author trys to make comparison on some complimentary contents between Chinese and English. This part mainly focuses on appearance, weight, friendship and possessions. These four topics are highly mentioned in people's conversations at home and abroad. But compliments expressed with different ways due to the variation of cultures and differ in many values.

1. Compliments on appearance

The ancient said, "Everyone wants to be beautiful."Both Chinese -speaking people and English-speaking people have the same opinion. Therefore, appearance-involved compliments are ubiquitous and never limited by age, social status, 
occasions and familiarity. However, Chinese and English also have many differences. For example, in English, appearance-concerned compliments are dominant. People are generous to show their compliments about others' appearance, especially something new, like new haircut, new clothes and shoes and etc. These compliments are concerned with varnished beauty and time-efficient. For instance, "You look beautiful today!'In this sentence, we can pay attention to two main words: "look" and "today."The first word illustrates that the compliment highlights the speaker's personal feelings rather than the essence of recipient's beauty. The word "Today" states the timeliness of this compliment, not yesterday or forever, just attain importance to "today". By comparison, Chinese used to compliment others' natural beauty and these compliments aren't time-limited. "A born beauty." is considered to be the highest evaluation to others' appearance. They often say "You are beautiful, you are a born beauty."This compliment highlights the beauty of the recipient's rather than the speaker's own feelings. In addition, compliments on appearance have gender differences between Chinese and English. People in English, whatever males or females, never mind to compliment others or receive compliment from others. Males can compliment both males and females about their appearance directly. Females are the same with males. Whereas, people in Chinese have a habit which is different from English habits. The compliments usually happen among females. Females are able to compliment females without quantitative and age limitation. But It's impolite for males to compliment females' appearance directly, in particular, specific body parts, because females may think it's frivolous.

2. Compliments on weight, friendship and possessions

As we know, "weight" is a sensitive word in daily conversations. In China, if people say: "You are fatter than before."That will be regarded as a compliment to the recipient's good living conditions. "fat" is often relating with "wealthy" and "a feature of officer" in China, because most people believe that it is the rich man who is able to eat well and have a high-quality life to put on weight. On the contrary, people do not take it as a compliment if someone says: "You've put on quite a lot."They think the "fatter figure" is a sign of their declined physical quality and if get fatter, they will consider it means they are too lazy to do some exercises and taking a causal approach to diet. So people will take this kind of compliment as an impolite speech act and even will misunderstand that's an irony. Therefore, weight is not suitable to be used as compliment contents in English interactions. But with the blending of various cultures, Chinese is gradually to receipt"weight lost" as a compliment, too.

Under the circumstance of Chinese traditional cultures, friendship plays a significant role in daily interactions. There is a duty of responsibility among friends. They maintain an invisible affiliation among themselves so that they usually choose to go through thick and thin together. Friends have preference for mixing things and emotions up. This connection is based on emotions and oriented by interpersonal relationship. The responses for friends and strangers are usually different. However, English focus much more on activities, interests and works. They have no need of sharing thick and thin together and tend to separate favors and matters cleanly. So whatever strangers or friends, if they do favors for others, they always get "Thank you." for respond. We often hear this sentence in our daily life:

"You have so much money!"There is no doubt that it is a compliment in China. It seems that the rich men are extraordinary. The more money someone has, the more successful he is, hence people are delighted to compliment someone who has large amount of possessions. Whereas, the effect in English-speaking countries is other than in China. Personal possessions is no longer the judgement criteria of success. Because they advocate self-made possession rather than inherited property and take money as the sign of living standards' improvement. Therefore, "You have so much money!"'is not a compliment in English-speaking countries.

\section{B. Semantic Structures of English and Chinese Compliments}

Manes and Wolfson concluded that "compliment has a high degree of regularity in the study of compliment."(Holmes, Brown.1987, p.529). The forms of English compliments barely can be regarded as formula. Manes and Wolfson categorized the English compliments into nine types and the first three forms with a high-frequency use, especially the first form which takes over 50 percents. The author mainly mentions the first three forms to summary the characteristics of English complimentary forms. Here are the three forms:

1. NP +be/look +(really/very)+AP+(PP). $(53.6 \%)$

$\mathrm{Eg}$ : Your dress is/looks (really) beautiful.

2. I (really)like/love+NP.(16.1\%)

$\mathrm{Eg}$ : I really like/love your shoes.

3. $\mathrm{PRO} / \mathrm{NP}+\mathrm{be}+(\mathrm{a})+($ really $)+(\mathrm{AP})+\mathrm{NP} .(14.9 \%)$

Eg: That's a really wonderful model plane.

From the research on these kinds of compliments, Manes and Wolfson (1981) also found that there are almost positive adjectives, like nice, good, pretty or beautiful, and Verbs, such as "love" and "like", as well as some formulaic sentence structures, for example:"I love/like......."In English, the key words in compliments are centre on adjectives an verbs, but in Chinese, according to the research on Chinese compliments of Ye(1995), words centre on adjectives for $54.5 \%$, adverbs for $27.4 \%$, noun for $15.8 \%$ and verbs for $2.3 \%$.But most Chinese adjectives are different from English adjectives, English adjectives are full with boundary meanings. Let's take "good" for instance, "good" can not only be used to modify a person's character, appearance, clothes, etc, but also can modify everything good. In other words. English adjectives in compliments mainly to show general meanings. However, many adjectives in Chinese 
compliments need to pay much attention to the detailed meanings, or it will cause the opposite meaning and irritate the addressees, especially the use of some idioms with historical allusions in China. As for the verbs both in English and Chinese compliments differ in the use of "like" and "love". It's common to see the compliment "I like your nice clothes." in English, but it's not a compliment for a Chinese-speaking person. Here is a conversation between a English speaker and a Chinese speaker to show the reason.

A: You have got a nice coat!

B: Thank you. My sister bought it in Shanghai. Do you really like it?

A: Oh, yes. It's fine, I like its beautiful color.

B: Well, if you really like it, I will ask my sister to buy one for you.

(Li Yanfen,1999,(On Cultural Distinction Between the East and the West in English and Chinese Praises))

From this conversation, we are not difficult to find that A just wants to start a topic by compliment B' coat, but B misunderstand A's meaning which A wants to buy the same coat. Therefore, the structure "I like or love...." is rarely found in Chinese compliments, because it's easily misinterpret that someone desires for something, and it's also out of the step with habit of Chinese expression.

\section{COMPARISON OF ENGLISH AND CHINESE RESPONSES TO COMPLIMENTS}

A: If you meet an American woman and say: "You are so pretty."She will responds two words.

B: What are they?

A: Thank you. If you meet a Chinese woman and say the same words, she will also answer with two words.

B: "Thank you?"

A: No, "Buzz off."

(Quoted from a Chinese talk show, cited in Chen,1993, p.49-50)

From this talk, we can see two diametrically opposite results due to the cultural conventions: American woman is very happy and glad to accept the compliment while the Chinese woman is very irritated and angry to refuse it. In order to make proper responds to others' compliments when participate in cross-culture social activities. The author mainly aim to make comparison on compliment responses strategies and characteristics between Chinese and English.

\section{A. Patterns and Characteristics of Chinese and English Compliment Responses}

As a part of compliments, compliment responses always vary from various cultural contexts. Many scholars have done many specialized researches on compliment responses about its patterns, maxims and differences which caused by cultural diversity at home and abroad. American linguist, Herbert, summarized 12 compliment response patterns that people almost from different countries possess:

\begin{tabular}{|ll|}
\hline 1, appreciation token & 2.,praise upgrade \\
\hline 3,comment acceptance & 4, comment history \\
\hline 5,reassignment & 6, return \\
\hline 7, questioning & 8. scale down \\
\hline 9,qualification & 10, disagreement \\
\hline 11, no acknowledgement & 12, request explanation \\
\hline
\end{tabular}

According to Herbert's categories, there are many response patterns to concerned compliments and these patterns are summarized from different people and occasions. Just like a person's habit, different kinds of languages may have different emphasis duo to the customs of language expression. Because more and more people who possesses diverse cultural contexts have a high-frequency use of compliments and compliment responses, the combination pattern emerged at the right moment. People are apt to choose the most proper way to give a respond to others' compliments. Among these 12 patterns, the author holds the view that pattern 5,6 and 8 are responses which are equipped with rich Chinese national characteristics. Most Chinese tend to make respond to compliments like this:

(1)

A: You are such a good player..

B: You played it well, too.

(return)

(2)

A: Your scarf is fashionable.

B: Yeah , my sister bought it from Beijing. Do you know Beijing? (reassignment)

(3)

A: You did a good job.

B: Oh, just so-so. (scale down)

As we can see, the conversations above are Chinese-style compliment responses. People used to respond the compliments in a modest way and these response patterns can embody the mutual concession, politeness and courtesy characteristics of Chinese. By contrast, patterns 7 and 10 are suit the English expression. Let's see some examples again:

(4) 
A: I admire your hard offering.

B: You've never seen the other side of me. (disagreement)

(5)

A: I like your T-shirt, it's so smart.

B: Really? Isn't it bad? (questioning)

Those two examples show that people in English used to be straightforward to respond others' compliments. They dare to express their own ideas directly. That's also meet their on-limits and direct principles. The other response patterns, except what the author have mentioned above, have consensus functions both in Chinese and English. In addition, more and more people from different countries tend to use the combination pattern, that is, people mix two or more kinds of response patterns to make response and this is a new trend of compliment responses nowadays. The reason why this trend appeared is that different cultures mingled gradually. Although many researches show when someone is complimented by others, most Chinese used to reject or elude compliment while English recipients prefer to agree with the speakers.

\section{B. The Reason of Compliment and Responses Differences between English and Chinese}

As everyone knows, compliment, as a speech act, always carries the culture of this language. In English, compliment preferentially starts with the first person while compliment usually begins with the second person in Chinese. That is, American have a strong sense of self-awareness and independence, and the culture of this nation put the emphasis on individuality, including personality, values and dignity. Because deeply influenced by Christianity, people in the west dream to be a independent person who is faithful to his own feelings, as well as a person who has strong self-awareness. individualism is their most important and basic values, they has made no secret of their self-confidence and sense of honor, they also rejoice with the wild excitement for success. On the other hand, America is a emerging nation of immigrants so that they think everyone is equal and there is no lowliness and nobleness. In most west families, Dads will say "Thank you" to their sons if sons do some favour for their dads. That is also the reason why most English speakers choose to agree with others' compliments. On the contrary, China is an ancient which has a feudal culture for more than 2000 years. Therefore, there still exists unequal ideas among Chinese. So when meet the speakers' compliments, Chinese always take rejection, return or scale down for the first action and sons are rarely get "Thank you." from their dads if sons help their dads to do something. What's more, most Chinese have preference for living or working together with groups and group benefit is the most crucial benefit. They don't have strong individualism and dare to express their own feelings if his social status is lower than others. For Chinese, The compliments are mean to shorten the distance and maintain a friendly relationship with others. In addition, Chinese used to behave modestly and keep courtesy when they participant in interactions, so they are not generous with expressing their true feelings to others. In short, those differences between Chinese and English are caused by the various cultural contexts.

\section{CONCLUSION}

As a speech act, compliment has its specific meaning and functions both in Chinese and English, as well as other languages. However, language environment is too important to be without for compliment and the expression of compliment response also varies from different cultural context. In addition, people have various emphasis when they compliment others, let's take the content "appearance" for instance," appearance" always come firstly in English while in Chinese, it's not the primary one. Compliment is also a speech act which has rich formula features, in particular, the compliment responses which possess boundary patterns both in Chinese and English. But compliment and compliment response may express with different ways, because language carries the nation's social and cultural characteristics. In English, people mainly stress on individualism, they dare to show their sincere feelings and try their best to keep equal position with others. But Chinese are careful to compliment others and keep modesty and be polite to others' compliment because of the deep cultural inheritance and deposits. There still exists many complimentary differences caused by different cultural diversity and need people to find out. It is indispensable to comprehend the west people's expression principles in real life. Duo to the differences of cultural background, the customary culture and factors of cultural judgement vary from nations, so that people should pay more attention to the ways of compliments and responds. So sometimes not all compliments will be considered to be a praise, if the compliments aren't expressed in proper ways, the recipients may feel ill at ease, even irritated. In order to use the compliments in appropriate ways and make responds properly to attain expected effects, this thesis is mainly to make comparison between Chinese and English compliments. The comparison contains complimentary contents, such as appearance, weight, friendship and possession, response patterns and characteristics of Chinese and English compliment responses. Only take a positive attitude to master and respect different cultures, people can properly use various languages to get along well with others.

\section{REFERENCES}

[1] Dai Fengfeng. (2017). A Comparative Study of Chinese and English Compliment Response Strategies and their cross-culture implications. Hefei: Science, education and Culture.

[2] Herbert, R. K. (1990). Sex-based differences in compliments behaviors. language in society,(19):201-224.

[3] Holmes. (1986). Compliments and compliment responses in New Zealand English. Wellington: Anthropological Linguistics. 
[4] He Mingzhi. (2002). A Comparative Study of English and Chinese Compliment Expressions and Responses and pragmatic. Failure. BeiJing: Journal of University of International Relations.(5)41-46

[5] Li Junru. (2007). A Contrastive Study of Compliments and Their Responses. Shanghai: Foreign Language Teaching, (04):21-26.

[6] Liu Weihong. (2003). A Comparative Analysis of Chinese and American Compliment Responses. ChangSha: HuNan University.

[7] Manes Joan. (1983). Compliments: a mirror of cultural values. Boston: Rowley Newbury House Publishers, Inc.

[8] Wang Jijie, Xu Zhenghua. (2005). A Cross-culture Comparative Study of Compliments and Their Responds. TianJin: Journal of Tianjin University (social Science Edition),(03):221-225.

[9] Yang Di. (2007). A Contrastive Pragmatic Study of English and Chinese Compliments and Their Responses. Harbin: Heilongjiang University.

Rongmei Yu was born in JiangXi province China in 1964. She received his Bachelor's degree in English Language and Literature from JiangXi Normal University, China in 1989.

She is currently a professor in Nan Chang Normal University, JiangXi, China. Her research interests include Intercultural Communication and English Teaching.

Prof. Yu is a member of JiangXi Translation Association and the teacher of Nan Chang Normal University. 